\title{
A.E. PЫXTOPOBA
}

\section{Анализ и построение рекламного образа библиотеки методом интервью с пользователем}

Реферат. За последние десятилетия реклама для библиотеки стала обязательной частью деятельности, однако подход к ее созданию во многом опирается на принятые стереотипы, выражающие самые распространенные представления о свойствах такого сложного явления, как целевая аудитория библиотеки. Реклама может выражаться через рекламный образ, содержащий не только объективную, но и субъективную информацию; в нем используются ассоциации, метафоры, эмоции, визуализация чего-либо, носящая обобщающий характер, т. е. к точным данным добавляется слой имплицитной информации, считываемый автоматически. Одна из проблем создания рекламного образа может заключаться в наличии противоречий между восприятием того, кто создает рекламу, основываясь на стереотипе, и ее адресата. Статья отражает опыт Государственной публичной научно-технической библиотеки Сибирского отделения Российской академии наук (ГПНТБ СО РАН) в исследовании двух групп - «Посетители мероприятий» и «Читатели». В исследовании приняли участие 326 человек (254 посетителя массовых мероприятий и 72 читателя ГПНТБ СО РАН). Апробирован метод полуформализованного интервью для получения актуальной информации, позволяющий лучше понять мотивацию и желания аудитории. Предполагается заранее составленный план со списком обязательных вопросов, при этом используются общие формулировки и их вариации, «близкие к тексту», при соблюдении общей логики в их последовательности.

Анализируются данные по распределению пользователей обеих групп («Посетители мероприятий» и «Читатели») по возрастным категориям и сферам занятости; частота посещений библиотеки; частота упоминаний форм работы, названных востребованными и признанных интересными в обеих группах; частота упоминаний предпочитаемых каналов информирования. Представлены основные позиции для формирования рекламного образа библиотеки. Показана целесообразность применения метода полуформализованного интервью в корректировке рекламного образа библиотеки и кампании по продвижению мероприятий, ресурсов и услуг на его основе как для отдельных групп, так и для нескольких сегментов параллельно в случае,

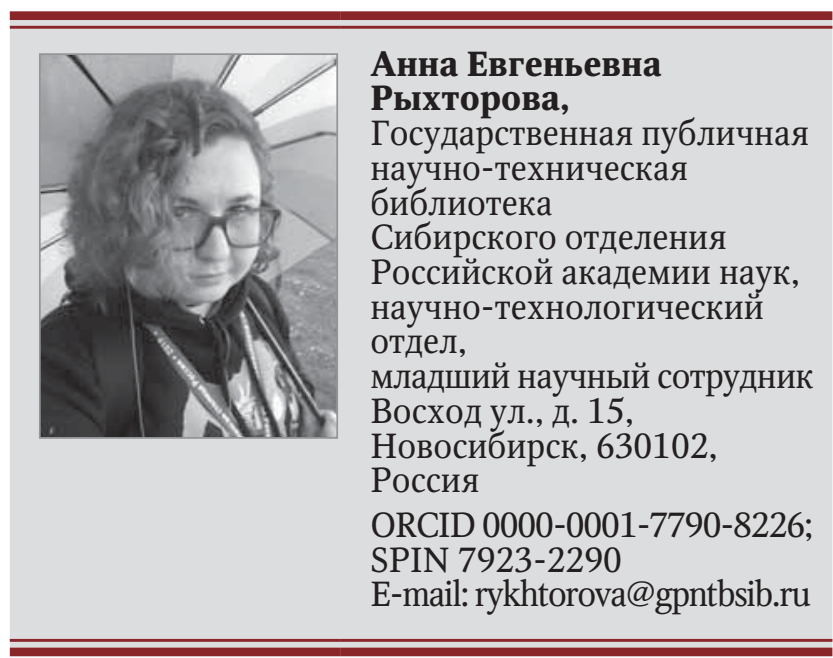


если мероприятие или услуга библиотеки не имеют специфического адресата. Раскрывается методика работы, которая может быть применена в анализе рекламного образа для иных библиотек.

Ключевые слова: организация библиотечного дела, рекламная деятельность библиотеки, рекламный образ библиотеки, библиотечный маркетинг, интервью, целевая аудитория библиотеки, читатель, изучение пользователя, изучение читателя.

Для цитирования: Рыхторова А.Е. Анализ и построение рекламного образа библиотеки методом интервью с пользователем // Библиотековедение. 2020. T. 69, № 6. C. 655-667. DOI: 10.25281/0869-608X-2020-69-6-655-667.

$\Pi$ ереход в интернет-среду и активное потребление информации меняют условия работы библиотеки. Сейчас наиболее ценными ресурсами становятся время и внимание пользователя. Необходимо убедить читателя уделить время библиотеке, объяснив, что такие траты в конечном итоге будут не просто оправданы, но станут лучшим его выбором. Для достижения данной цели библиотеки используют в своей деятельности маркетинговый подход и чаще всего средства рекламы. Реклама, будучи инструментом маркетинга, стала обязательной частью деятельности библиотеки за последние десятилетия, но подход к ее созданию во многом опирается на принятые стереотипы. Они выражают самые распространенные представления о свойствах таких сложных явлений, как целевая аудитория библиотеки и ее место в современном обществе. Если тот, кто создает рекламу, имеет устойчивое стереотипное представление о ее адресате, не соответствующее действительности, возникает противоречие. Этот стереотип мешает созданию рекламного образа, с которым целевая аудитория сможет самоидентифицироваться. В таком случае встает вопрос об актуализации представлений о мотивах и потребностях пользователей, для чего может быть использован гибкий инструмент - полуформализованное интервью.

\section{Рекламный образ библиотеки}

За последние десятилетия место библиотеки в обществе рассматривалось с различных позиций. Принимая во внимание, что «центр тяжести глобальных процессов и перемен сегодня как никогда связан с коммуникационными процессами, разворачивающимися в глобальном социокультурном пространстве» [1, с. 104], когда такое пространство, связанное через Интернет, функционирует не как «место» в традиционном понимании, а как «прерывистое созвездие про- странственных фрагментов, функциональных частей и социальных сегментов» [2, с. 102], библиотека старается развиваться в различных направлениях: и как информационный посредник, поставщик и/или навигатор в многообразном потоке информации, и как «третье место». Одним из трендов такого развития, в частности, является рассмотрение библиотеки как территории креатива: «В этом пространстве так много разнообразных направлений, там может быть реализовано множество потенциальных программ и мероприятий, охватывающих широкий круг тем» [3, с. 54]. При этом указывается, что в результате продолжающегося поиска библиотека в настоящее время находится в неопределенной ситуации. Одни библиотеки напоминают места культурных встреч, другие придерживаются традиционного акцента на собственные фонды [4] или ориентируются на переход от тихой, индивидуальной работы читателей к организации пространства кооперации, оснащенного современной техникой [5]. Несмотря на происходящие изменения в позиционировании, «за последние 20 лет имидж библиотек не изменился, в то время как реальный образ сформировался далеко не похожим на те представления, которые мы имеем» [6, с. 55]. Отдельные исследования показывают, что библиотека в основном продолжает рассматриваться либо как досуговое учреждение культуры, либо как место учебы, к которому нет необходимости возвращаться по окончании образовательного процесса [7].

Для изменения ситуации библиотечные специалисты продолжают работать над созданием нового имиджа своих учреждений. Одним из наиболее распространенных средств остается реклама, точнее, создание рекламного образа, который, вызывая достаточно сильную эмоционально-психологическую реакцию и ассоциации, «становится в настоящее время непременным условием обеспечения эффективности коммуникативного процесса, выраженной в 
целевом поведении аудитории, контактирующей с сообщением» [8, с. 97].

Рекламный образ при этом содержит не только объективную информацию (даты, адреса, время и пр.), но и субъективную. В нем используются ассоциации, метафоры, эмоции, визуализация чего-либо, носящая обобщающий характер, т. е. к точным данным добавляется слой имплицитной информации, считываемый автоматически. Конечная цель рекламного образа при этом - «сформировать у реципиента позитивное отношение к производителю или товару, а также выработать потребительские мотивы» [9, с. 312]. Рекламный образ, связываемый с библиотекой, призван побуждать пользоваться ее ресурсами и услугами, оставлять определенное позитивное впечатление, ассоциацию. Цель достигается через задействование трех механизмов: сублимации, проекции, идентификации. В контексте библиотек наибольший интерес представляют последние два, где проекция заставляет пользователя переносить свои чувства и переживания с героев рекламы на себя, а механизм идентификации, наоборот, показывает пользователю, что в рекламе ключевой фигурой выступает именно он [10].

Сложность заключается в том, что рекламный образ функционирует как совокупность трех основных элементов: отражение в сознании того, кто рекламу создает; отображение самого объекта рекламы; отражение и запечатление в сознании пользователя. Таким образом, одна из проблем создания рекламного образа состоит в наличии противоречий между восприятием того, кто создает рекламу, и ее адресата. Так, с учетом медленных темпов омоложения кадрового состава противоречие может создать стереотип, аккумулирующий некий стандартизированный коллективный опыт библиотечных сотрудников по восприятию как библиотеки, так и пользователей. Такой стереотип, основанный на восприятии прошлого либо не устоявшегося настоящего библиотеки и ее деятельности, мотивов и целей пользователей, может мешать созданию рекламного образа. «...Процесс стереотипизации происходит медленно и основывается, как правило, на устаревших культурных кодах» [11, с. 446], поэтому с течением времени образ, в котором используется стереотип, может вызывать раздражение у пользователей. Процесс самоидентификации целевой аудитории с этим образом, равно как и механизм проекции, может разрушиться. Следовательно, для построения более эффективного рекламного образа необходима актуализация представлений о пользователях и их мотивах.

\section{Интервью с пользователем библиотеки: методика}

Как правило, библиотеки, изучая читателей, сосредотачиваются на разработке опросов фокус-групп в целях изучения того, как пользователи различных групп ищут услуги или ресурсы в своей повседневной жизни. При анкетировании, иногда совмещенном с наблюдениями и/ или экспериментами, обычно спрашивают о библиотечных услугах, а также о способах поиска информации $[11 ; 12]$. Кроме того, его проводят с целью лучшего представления об успешности поиска в каталогах конкретной библиотеки [13] и общего уровня удовлетворенности как электронными коллекциями [14], так и библиотечными услугами в целом [15]. Опросы нацелены также на определение места библиотеки в жизни общества [16; 17], однако в них отсутствует гибкость, позволяющая задать дополнительные вопросы либо предоставить пользователю больше свободы в выражении своего мнения. Также на их основе трудно составить цельный рекламный образ, так как информационные привычки, поведение пользователя представляют собой только один аспект такого явления, как целевая аудитория библиотеки.

Другой метод получения актуальной информации для построения рекламного образа, который применяется значительно реже, - полуформализованное интервью с пользователями. В рамках такого интервью предполагается заранее составленный план со списком обязательных вопросов, при этом используются общие формулировки и их вариации, «близкие к тексту», при соблюдении общей логики в их последовательности. Респондент может самостоятельно переходить с одной темы на другую: например, от удовлетворенности текущими услугами библиотеки к наиболее интересным для него услугам или мероприятиям, либо к удовлетворенности материально-техническим обеспечением. Кроме того, пользователь может дать более развернутую информацию о себе и своих взглядах, интересах, отвечая на вопрос о более интересных для него мероприятиях и (или) услугах, чем во вводной части знакомства. Такой подход призван смягчать искусственность беседы, провоцировать оригинальные ответы и поощрять свободные высказывания респондентов.

Частичная формализация (заранее составленный список вопросов, отвечающий уже определенным пунктам для анализа) позволяет получить сравнимые и пригодные для типологизации и дальнейшей математической обработки данные. В то же время «полуформализованное интервью 
достаточно гибко и восприимчиво, чтобы уловить и зафиксировать непредвиденные, но интересные повороты темы или скорректировать явно искаженное восприятие тех или иных вопросов» [18, c. 31]. Такое интервью подразумевает практически равноправные роли интервьюера и респондента, не только интервьюер корректирует ход беседы в соответствии со своими целями, но и «респондент как носитель информации оказывает влияние на последовательность рассмотрения тем в интервью, на его темп» [19, с. 24]. Элементы творческого подхода, а также живое неформальное общение, включающее индивидуальный подход к респондентам, позволяют получить бо́льший объем информации для последующей обработки, нежели при заполнении опросников либо автономной обработки статистических данных.

В качестве базы исследования для выработки применимой для создания рекламного образа библиотеки методики и ее апробации была определена Государственная публичная научно-техническая библиотека Сибирского отделения Российской академии наук (ГПНТБ СО РАН). Посетители библиотеки были условно разделены на две группы - читателей и посетителей массовых мероприятий, а в качестве метода был выбран опрос.

В исследовании приняли участие 326 человек (254 посетителя массовых мероприятий и 72 читателя ГПНТБ СО РАН). Беседа в свободной форме, отвечающая заранее определенной цели исследования и содержащая ряд обязательных вопросов, занимала от 2 до 10 минут на одного респондента (в зависимости от его предрасположенности к разговору) и записывалась на диктофон для последующей расшифровки и формализации данных. Отдельные сведения, связанные с поведением респондентов, не отражаемые записью, фиксировались письменно. Основными пунктами для анализа стали:

- возраст;

- тип занятости;

- сфера занятости;

- область интересов;

- частота посещений библиотек;

- удовлетворенность текущим уровнем обслуживания;

- удовлетворенность текущим ассортиментом ресурсов и услуг;

- удовлетворенность текущей организацией библиотечного пространства;

- удовлетворенность текущим уровнем материально-технического обеспечения;

- наиболее востребованная форма работы;

- наиболее интересная, желаемая форма работы;

- предпочитаемые каналы информирования о мероприятиях;

- примечания (мотивы похода в библиотеку, пожелания и рассуждения пользователей, заметки, вытекающие из наблюдения за пользователями в ходе интервью).

Итоговый массив данных для обработки был собран в две таблицы (для посетителей мероприятий и читателей) и впоследствии обрабатывался средствами Microsoft Excel.

\section{Интерпретация данных}

Следующим этапом исследования стала интерпретация полученных данных. Между двумя группами пользователей ГПНТБ СО РАН - «Посетители мероприятий» и «Читатели» - были отмечены существенные отличия в возрастных

Таблииа 1

Распределение респондентов по возрастным категориям

\begin{tabular}{|c|c|c|}
\hline \multirow{2}{*}{$\begin{array}{l}\text { Возрастная } \\
\text { категория }\end{array}$} & \multicolumn{2}{|c|}{ Доля пользователей (\%) } \\
\hline & $\begin{array}{c}\text { группа «Посетители } \\
\text { мероприятий» }\end{array}$ & группа «Читатели» \\
\hline $14-18$ & 23 & - \\
\hline $19-25$ & 16 & 10 \\
\hline $26-35$ & 36 & 16 \\
\hline $36-45$ & - & 22 \\
\hline $46-60$ & 14 & 23 \\
\hline $60+$ & 11 & 29 \\
\hline
\end{tabular}

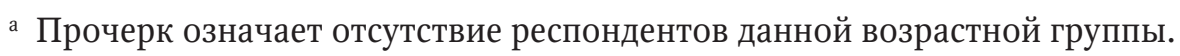


Военно-оборонный комплекс

Горнодобывающий комплекс

Госслужба

Здравоохранение

Информационные технологии

Искусство

Культура

Неорганическая химия

Образование

Общественная деятельность

Общественные науки

Органическая химия

Промышленность

Развлечения и отдых

Строительство

Торговля

Туризм

Юриспруденция

Ядерная физика

Студент

Ученик школы

Отсутствует

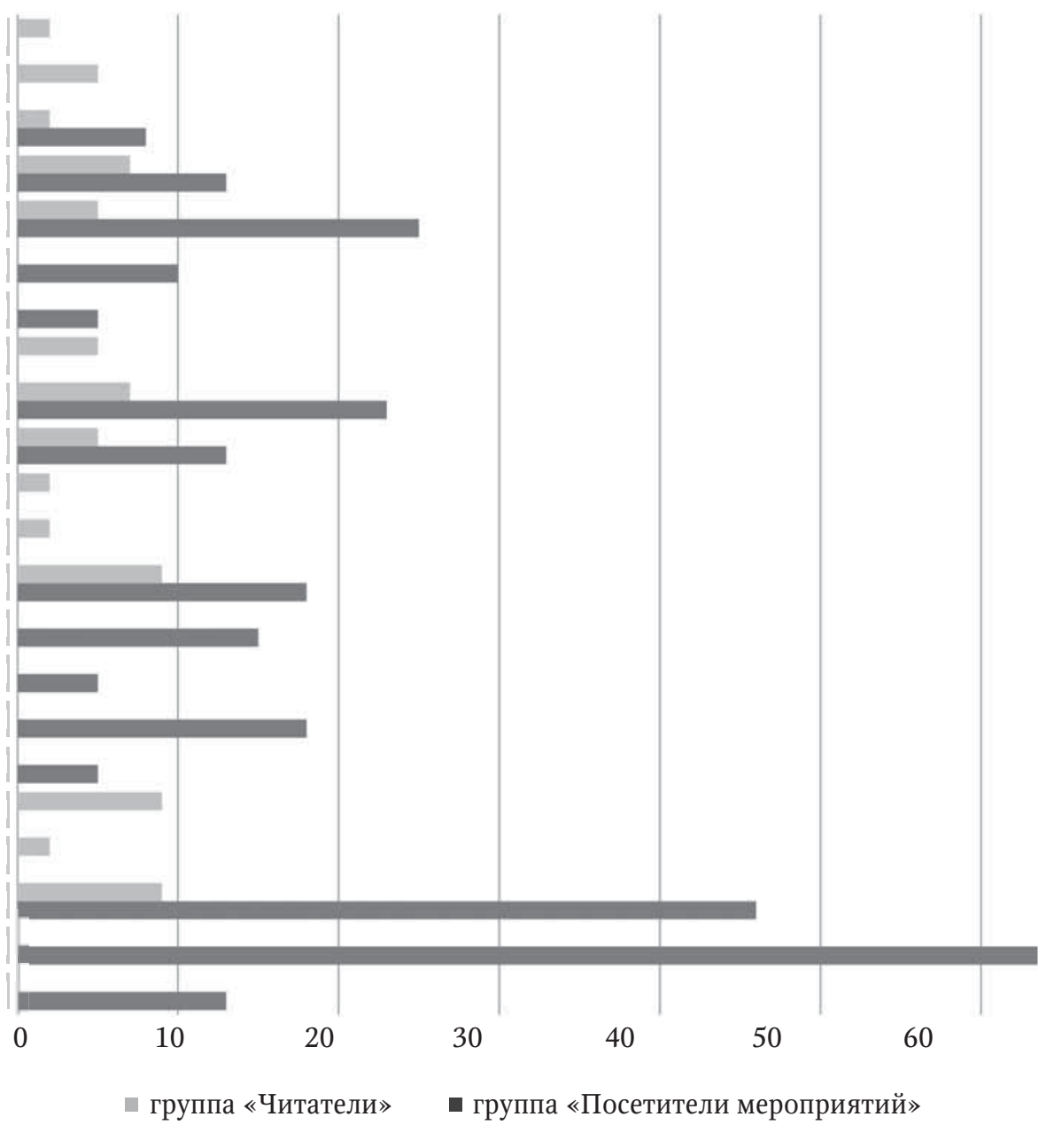

Рис. 1. Распределение респондентов по сферам занятости

категориях (табл. 1). Кроме того, при преобладании специалистов и научных сотрудников группа «Читатели» по показателям посещаемости, как уже отмечалось в предыдущих исследованиях [20], значительно отстает (этим объясняется меньшее число респондентов).

Далее была определена сферах занятости (рис. 1). Отметим, что студенты из числа посетителей мероприятий обучались в таких сферах, как педагогика, экономика (преимущественно), юриспруденция, а студенты-читатели - в основном в сфере информационных технологий (IT) и юриспруденции. В силу специфики занятости при рассмотрении корелляций и связей сферы занятости и сфер интересов, студенты рассматривались в группах, соответствующих профилям обучения.

Выявлено, что интересы пользователей варьируются: среди посетителей мероприятий это преимущественно психология, экология, религия, экономика, история, культура, искусство; среди читателей - юриспруденция, экономика, иностранные языки и изобретательская деятельность. При более подробном рассмотрении интересы в целом соответствуют профилю обучения/работы для посетителей мероприятий, но не вполне - для читателей. Так, среди посетителей мероприятий, работающих/обучающихся в сфере IT, наиболее часто упоминаемые интересы относятся к физико-математическим наукам, но для читателей из той же сферы лидирует изобретательство; среди посетителей, занятых в сфере здравоохранения и медицины, в интересах наиболее часто упоминается отраслевая информация, а среди читателей - юриспруденция и отраслевая информация; среди посетителей, занятых в сфере образования, как область интересов лидирует педагогика, а для читателей - экономика.

Во время интервью отмечалось, что посетители мероприятий, в случае обращения за ресурсами или услугами библиотеки, а также при участии в мероприятиях менее склонны ориентироваться на названные интересы, и 


\section{Частота посещений библиотеки группами пользователей}

\begin{tabular}{|c|c|c|c|c|c|c|}
\hline \multirow{2}{*}{$\begin{array}{c}\text { Возрастная } \\
\text { категория }\end{array}$} & \multicolumn{7}{|c|}{ Частота посещений $^{\text {a }}$} \\
\cline { 2 - 7 } & Никогда & Очень редко & Редко & Часто & Очень часто & Регулярно \\
\cline { 2 - 7 } & & \multicolumn{7}{|c|}{ «осетители мероприятий»/ «Читатели» } \\
\hline $14-18$ & $44 /-$ & $9 /-$ & $5 /-$ & - & - & - \\
\hline $19-25$ & $7 /-$ & $2 /-$ & $9 / 2$ & $9 / 5$ & - & $14 /-$ \\
\hline $26-35$ & $28 /-$ & $32 /-$ & $18 /-$ & $12 /-$ & $2 / 12$ & - \\
\hline $36-45$ & - & - & $-/ 2$ & $-/ 5$ & $-/ 5$ & $-/ 5$ \\
\hline $46-60$ & $12 /-$ & $2 /-$ & $9 / 2$ & $9 / 5$ & $2 / 2$ & $-/ 7$ \\
\hline $60+$ & - & $2 /-$ & $5 /-$ & $12 /-$ & $2 /-$ & $7 / 21$ \\
\hline
\end{tabular}

a Прочерк означает отсутствие респондентов данной возрастной группы.

более - на наполненность мероприятия событиями, насколько запоминается его оформление, можно ли занять на мероприятии детей (в случае семейного посещения). Читатели, в свою очередь, более склонны вписывать свои личные интересы в рабочую/учебную деятельность, а библиотеку они рассматривают с точки зрения получения полезной для такой деятельности информации, но не как рекреационное учреждение.

Далее было установлено, что для группы «Посетители мероприятий» характерна абсолютная незаинтересованность в библиотеке в качестве поставщика информационных ресурсов на фоне интереса к ней как к площадке живого общения, исключающего сетевой информационный шум. Частота посещений библиотеки для этой группы, а также для группы «Читатели», представлена в табл. 2, где «никогда» приравнивается к первому посещению, когда человек пришел именно на мероприятие и не высказал интереса в дальнейшей работе с ресурсами библиотеки; «очень редко» - посещения реже одного раза в год; «редко» - посещения 1-2 раза в год; «часто» - от 2 до 10 раз в год; «очень часто» $-1-2$ раза в месяц и «регулярно» - более 2 раз в месяц. Посещения библиотеки до категории «часто» для респондентов из группы «Посетители мероприятий» привязаны к массовым мероприятиям; отмечалось, что после их посещения у пользователей не возникало желания приходить в библиотеку для удовлетворения информационных потребностей. Кроме того, посетители в возрасте от
14 до 25 лет, являющиеся учениками школы и студентами и отметившие свою незаинтересованность, также пояснили, что на мероприятия приходят потому, что их привел преподаватель. Для них характерны такие пояснения: «все лучше, чем сидеть на уроках», «хочется уйти домой пораньше».

Наибольшие корреляции между уровнем удовлетворенности обслуживанием, материально-техническим обеспечением, ассортиментом и организацией библиотечного пространства для групп старше 19 лет были отмечены именно с частотой посещения библиотек. Так, наиболее удовлетворены посетители массовых мероприятий, посещающие библиотеку «редко» и менее; наименее удовлетворены читатели, посещающие библиотеку «очень часто» и более. Респонденты из группы посетителей мероприятий 14-18 лет преимущественно затруднились дать оценку. Большую неудовлетворенность, особенно среди молодежи, вызывает уровень материально-технического обеспечения и организации библиотечного пространства, при этом такая оценка связана с «устаревшей техникой» и «отсутствием мягкой мебели и вентиляции».

Респонденты группы «Посетители мероприятий» в ходе общения наиболее часто так или иначе ссылались на необходимость «вырваться из информационного шума», создаваемого как в интернет-пространстве, так и традиционными СМИ. Обговаривалась необходимость места с ограниченным «живым» общением, а также лимитирование поступающей информации. Это согласуется с обсуждаемыми специалистами раз- 


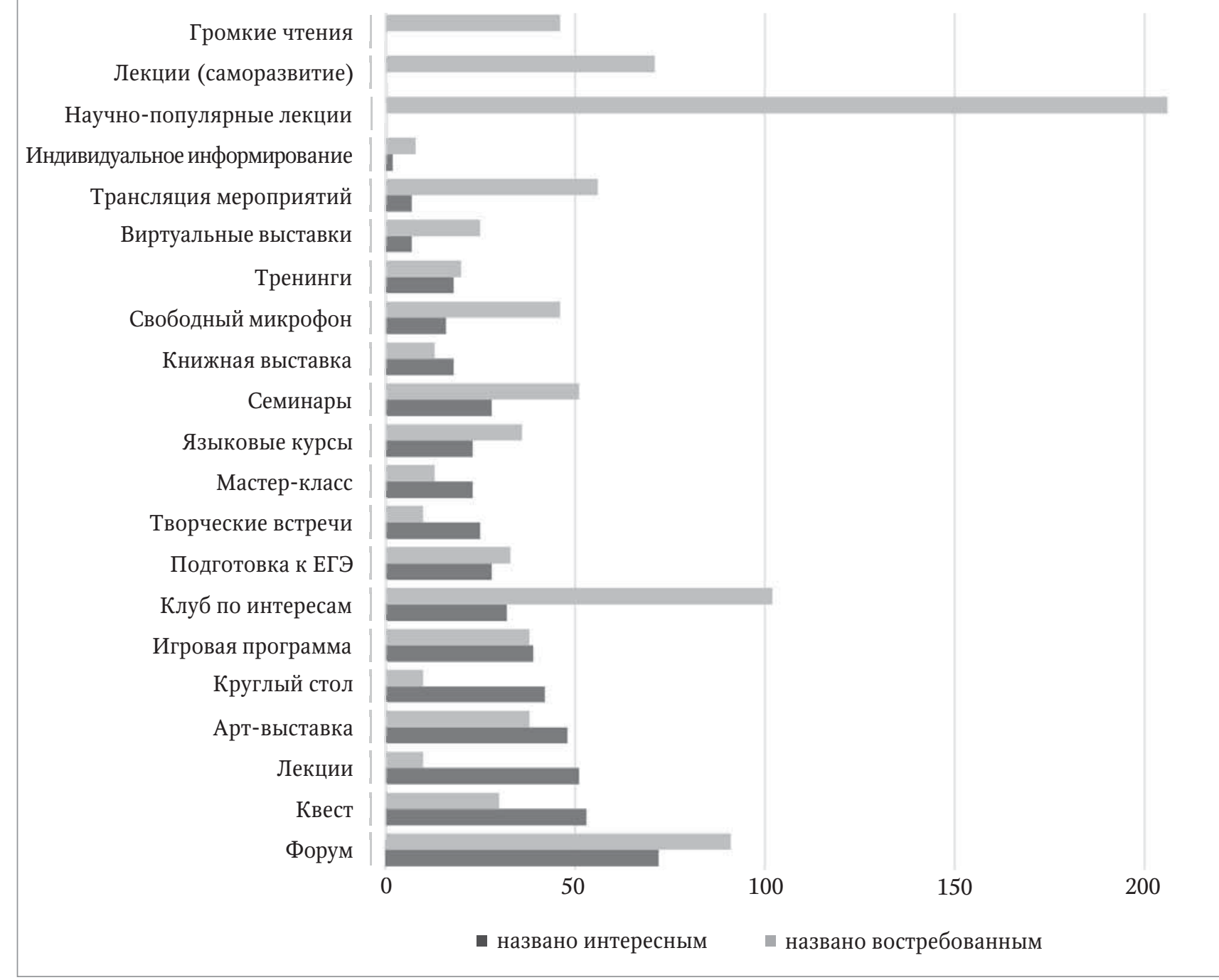

Рис. 2. Частота упоминаний форм работы, названных востребованными и признанных интересными, в группе «Посетители мероприятий»

личными «патологиями информации», которые вызывают наше современное состояние, включая информационную перегрузку, информационную тревогу и разочарование в непостоянстве цифровой информации [21]. Также посетители от 25 лет и старше, отмечавшие частоту посещений до категории «очень часто», делали уточнения о том, что для них важно не столько чтение, сколько живое общение; часть из них признавала, что не читает книг ни в традиционном, ни в электронном виде, а необходимую в работе информацию предпочитает узнавать на форумах и в блогах специалистов. Наиболее характерен такой подход в среде IT-специалистов, представителей сфер туризма и развлечений.

Более частые посетители, высказывая интерес к ресурсам библиотеки, чаще упоминали абонемент художественной литературы как наиболее востребованный для них. Кроме того, представители сферы образования, юриспруденции, неработающие пенсионеры, а также студенты (посещающие библиотеку от категории «часто») жаловались на отсутствие выдачи научных изданий на дом, что пересекается с интересами группы «Читатели».

Здесь необходимо также отметить, что для группы «Посетители мероприятий» выявлены существенные различия в частоте упоминаний востребованных форм работы и форм, в которых пользователи заинтересованы сами (рис. 2). Установлено, что пользователи 46 лет и старше чаще всего упоминали формы работы, которые, по, их мнению, будут интересны молодежи, а не им самим. После ряда уточняющих вопросов было выявлено, что «востребованные» для этой группы мероприятия во многом не совпадают с «желаемыми» и «интересными» как пользователям возраста от 46 лет, так и многим предста- 


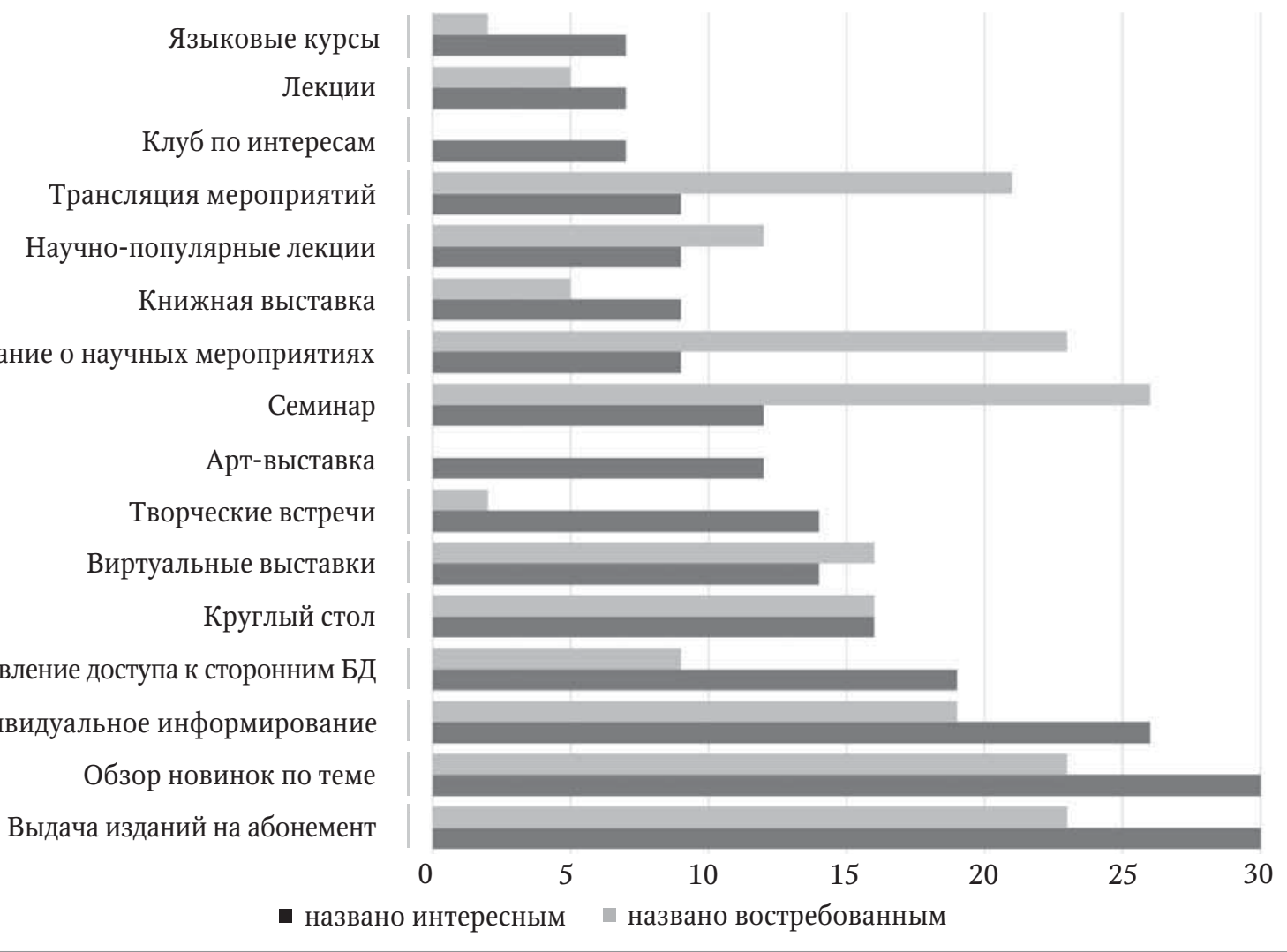

Рис. 3. Частота упоминаний форм работы, названных востребованными и признанных интересными, в группе «Читатели»

вителями молодежи. Поэтому, например, почти в два раза меньший интерес к форме «квест», разделение формы «лекции» на «научно-популярные лекции» и «лекции по саморазвитию», а также добавление «громких чтений». Следует отметить, что на фоне упомянутой ранее необходимости ограничения поступающего информационного потока многие пользователи проявляют заинтересованность в получении наиболее достоверной информации, и библиотека для них является учреждением, которое может ее предоставить. Такие посетители проявляли желание приходить чаще на научно-популярные лекции, доступно объясняющие достижения науки.

Для представителей группы «Читатели», напротив, в большей степени интересны информационные ресурсы и услуги (рис. 3), но при этом характерно слабое представление обо всем доступном их спектре. В ходе интервью установлено: читатели предпочитают обращаться за одними и теми же услугами, мало интересуясь нововведениями в обслуживании. Незаинтересованность объясняли сосредоточенностью на конкретных задачах и способах их решения через поиск информации (в основном пользователи 26-45 лет), отсутствием необходимости использования новых услуг (категория 60 лет и старше), представлением о библиотеке в основном как о хранилище редких, недоступных в Интернете книг и журналов (категория 19-25 лет). При этом респонденты и группы «Читатели», и группы «Посетители мероприятий» отметили, что в случае возникновения новых потребностей они либо спросят дежурного библиографа, может ли библиотека выполнить определенную работу, либо проведут поиск в Интернете (пользователи 19-35 лет), либо уточнят на сайте библиотеки (категория 46 и старше). Формы массовых мероприятий чаще упоминали читатели 60 лет и старше. Пользователи 26-60 лет чаще говорили об удаленных и индивидуальных формах, мотивируя свой выбор необходимостью как можно реже покидать свое рабочее место, так как работодатель ведет строгий учет рабочего времени. Пользователи категории 19-25 лет (обычно студенты), хотя и упоминали в качестве востребованных такие формы, как научно-популярные лекции и круглые столы, в качестве желаемых форм работы называли удаленные: трансляцию мероприятий, виртуальные выставки, а также индивидуальное информирование. Комментируя такое различие, респонденты отмечали следующие причины: сильная занятость в вузе, не позволяющая присутствовать на мероприятиях очно; желание получать и об- 


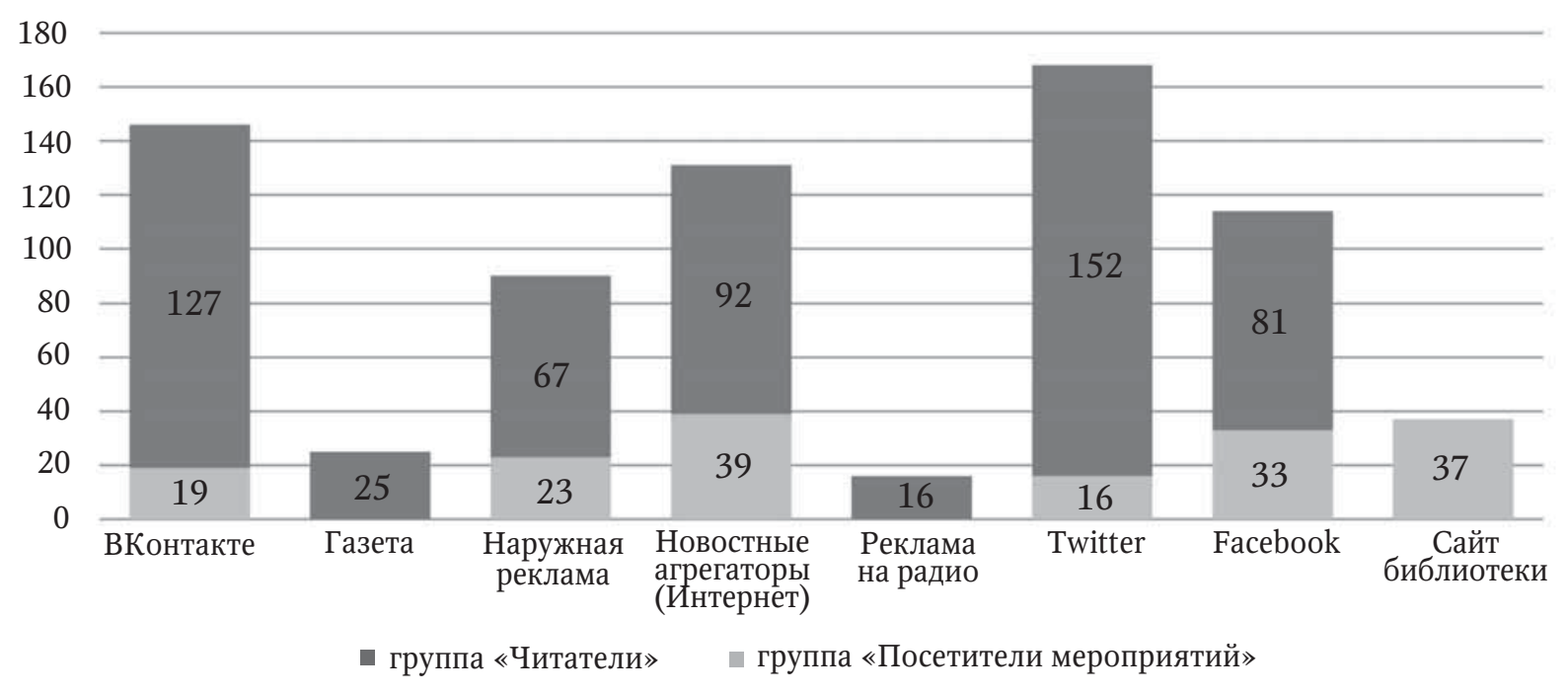

Рис. 4. Частота упоминаний предпочитаемых каналов информирования

рабатывать информацию в наиболее комфортных условиях; общая усталость и перегруженность, зачастую превалирующие над желанием социальной активности. Кроме того, некоторые из молодых людей признавали, что называли в первую очередь массовые мероприятия потому, что от них «этого ожидают» как от молодых и, как следствие, «социально активных», хотя на самом деле им в большей степени хочется потреблять избранную информацию в спокойной обстановке.

Что касается информирования пользователей о проходящих в библиотеке мероприятиях, введении новых услуг и ресурсов, то предпочитаемые каналы информирования для обеих категорий схожи и различаются в основном по возрасту респондентов (рис. 4). Отличия составили такие каналы, как печатные газеты, реклама на радио, информация на сайте библиотеки.

Так, рекламу в газетах и на радио называли в основном респонденты 60 лет и старше из группы «Посетители мероприятий», а получать информацию с сайта библиотеки предпочитают ее постоянные читатели; при этом информацию из новостных агрегаторов в группе «Читатели» отмечают, только если она касается реорганизации работы библиотеки или проведения массовых мероприятий. Посетители мероприятий предпочитают социальные сети и новостные агрегаторы, где информация о библиотеке поступает вместе с иными интересными для них событиями, т. е. специально ее ищут. Новостные агрегаторы и Facebook при этом упоминали преимущественно респонденты 36-60 лет, Twitter - ученики школы и студенты. Предпочтение наружной рекламе высказали преимущественно пользователи от 36 лет; те, кто добира- ется до места работы или учебы мимо библиотеки; посещающие ее очень часто либо регулярно.

\section{Возможности формирования рекламного образа библиотеки}

С помощью интервью представляется возможность выделить, помимо различной информации для улучшения работы библиотеки, опорные сведения, важные для отражения в рекламном образе (табл. 3). При этом массив респондентов может быть четко разделен на две группы в соответствии с выделенными особенностями - «Посетители мероприятий» и «Читатели».

Рекламный образ, формируемый библиотекой, может делиться на две части: одна больше ориентирована на читателей, другая - на посетителей. Несмотря на очевидную разницу интересов двух групп и возможность формирования сегрегированных рекламных кампаний, необходимо отметить, что речь идет также и о создании двух параллельных образов для одних и тех же мероприятий (не адресованных нишевой аудитории специалистов, разумеется), ресурсов и услуг с разными акцентами в субъективной информации и различными же каналами информирования для большего охвата аудитории.

Так, для пользователей из группы «Читатели» реклама определенного неспециализированного мероприятия размещается преимущественно на сайте библиотеки, наружная реклама - по пути следования к вузам (см. занятость, рис. 1). В социальных сетях она может акцентироваться, например, на возможности личного обсуждения тех или иных вопросов, 


\section{Опорные сведения для формирования рекламного образа библиотеки}

\begin{tabular}{|c|c|c|}
\hline Опорные сведения & «Посетители мероприятий» & «Читатели» \\
\hline Основная цель & $\begin{array}{l}\text { Живое общение, отдых от } \\
\text { информационного шума }\end{array}$ & Потребление информации \\
\hline Мотивация к посещению & $\begin{array}{l}\text { Наполненность мероприятия } \\
\text { событиями; «яркость» его } \\
\text { оформления; впечатления и сувениры; } \\
\text { возможность занять на мероприятии } \\
\text { детей; ориентация на интересы }\end{array}$ & $\begin{array}{l}\text { Получение уникальной полезной } \\
\text { информации; возможность личного } \\
\text { обсуждения (уточнения) получаемой } \\
\text { информации; ориентация на рабочую/ } \\
\text { учебную необходимость }\end{array}$ \\
\hline Важные факторы & $\begin{array}{l}\text { Большое количество людей для } \\
\text { «живого» общения; вентиляция; wi-fi; } \\
\text { возможность купить напитки и еду }\end{array}$ & $\begin{array}{l}\text { Мягкая мебель; вентиляция; } \\
\text { wi-fi; индивидуальные места работы; } \\
\text { обновленный парк ПК }\end{array}$ \\
\hline $\begin{array}{l}\text { Мероприятия/ } \\
\text { ресурсы и услуги }\end{array}$ & $\begin{array}{l}\text { Формы, способствующие } \\
\text { социализации }\end{array}$ & $\begin{array}{l}\text { Формы, способствующие получению } \\
\text { информации }\end{array}$ \\
\hline Канал информирования & Социальные сети & $\begin{array}{l}\text { Сайт библиотеки; социальные сети; } \\
\text { наружная реклама (по пути на работу) }\end{array}$ \\
\hline
\end{tabular}

соотносить тематику мероприятия с текущими событиями: сессия у студентов, распоряжения правительства в области научной деятельности и пр.

Для группы «Посетители мероприятий» та же реклама размещается в основном в социальных сетях, новостных агрегаторах и по пути следования к библиотеке. Реклама может показывать иные аспекты мероприятия: получение новых впечатлений, общение с единомышленниками, общая атмосфера и сопутствующие события, если они планируются.

Важно грамотное использование предпочитаемых каналов информирования обеих групп, а также недопущение излишних, ложных обещаний, например, выставление научно-популярных лекций исключительно «научными» в рекламе для «читателей» и исключительно «популярными» в рекламе для «посетителей». Необходима согласованность информации и, как сказано выше, акцентирование, подчеркивающее важные для той или иной группы мотивы и цели.

Библиотеки сегодня прикладывают огромные усилия к поиску «своего места» в структуре современного общества, введению новых форм работы и изучению пользователей. Но им не всегда хватает гибкости, понимания, что движет пользователями. Например, из заполненной анкеты об интересующих формах работы сложно увидеть, что студенты написали «научные лекции», так как от них ожидают именно это, а не потому, что они им интересны; сложно увидеть, что люди старшего возраста в первую очередь отмечают то, что интересно не им, а, по их мнению, молодежи, надеясь видеть больше молодых в библиотеке. Это препятствует формированию адекватного рекламного образа, способного повлиять на пользователей.

Предлагаемая методика анализа и формирования рекламного образа предполагает полуформализованное интервью для сбора сведений, на которые возможно опираться. Эффективность такой методики обусловлена гибкостью подхода к беседе, созданием условий для диалога, мягко модерируемого исследователем. Во время интервью пользователь получает возможность лучше раскрыть себя и предоставить больше информации для дальнейшей обработки за более короткий промежуток времени (по сравнению с заполнением анкеты) и более точной (по сравнению с наблюдением за пользователями). Такой диалог позволяет корректировать ход беседы, делать уточнения, задавать наводящие вопросы, а также получать больше комментариев от респондентов, которые в иных условиях сочли бы слишком долгим писать примечания в анкете.

Благодаря заранее определенному списку вопросов появляются сопоставимые и формализуемые данные для анализа. На их основе возможно выделение основных сведений, важных для формирования субъективной информации рекламного образа, путей его представления, а 
также создание базы для их уточнений в случае необходимости. Созданный и уточненный образ может использоваться как в рекламной кампании, нацеленной на конкретный сегмент аудитории библиотеки, так и для создания дифференцированных кампаний, продвигающих неспецифичные мероприятия. Они позволяют показывать библиотеку и как «третье место», территорию рекреации, и как информационное учреждение, создавая и закрепляя ее многосторонний образ.

\section{Список источников}

1. Адамъяни Т.З. Аудитория СМИ как субъект и объект коммуникативных взаимодействий // Человек. 2018. № 3. С. 96-107.

2. Соловъев А.В. Медиагород и человек: феномен отстраненной сопричастности // Человек. 2017. № 5. С. $100-107$.

3. Редъкина Н.С. Мировые тенденции развития библиотек: оптимизм vs пессимизм : (по материалам зарубежной литературы). Ч. 2 // Библиосфера. 2019. № 1. С. 49-58. DOI: 10.20913/18153186-2019-1-49-58.

4. Petersen J.H., Kooistra R.B. Rethinking Libraries in the Book Business // Public Library Quarterly. 2019. Vol. 13, № 1. P. 64-88. DOI: 10.1080/01616846.2019.1604040.

5. Shohama S., Klain-Gabbayb L. The Academic Library: Structure, Space, Physical and Virtual Use // The Journal of Academic Librarianship. 2019. Vol. 45, № 5. DOI: 10.1016/j.acalib.2019.102053.

6. Гришанин Н.В., Тулубъев В.Б., Лысанова Д.В., Любецкая А.Г. Имидж библиотеки в сознании молодежной аудитории: стратегии и тактики формирования паблицитного капитала // Коммуникология. 2019. Т. 7, № 2. C. 51-65. DOI: 10.21453/2311-3065-2019-7-2-51-65.

7. Fernández-Ardèvol M., Ferran-Ferrer N., Nieto-Arroyo J., Fenoll C. The Public Library as Seen by the NonUsers // Profesional de la información. 2018. Vol. 27, № 3. P. 659-670. DOI: 10.3145/epi.2018.may.19.

8. Лешуков А.Г., Чеботарев А.М. Дизайн коммуникационных продуктов: современные тенденции в культурном пространстве города // Вестник культуры и искусств. 2018. № 4 (56). С. 97-103.

9. Савченко Д.Г. О понятии «рекламный образ» // Вестник Московского государственного лингвистического университета. Гуманитарные науки. 2018. № 18 (816). C. 308-319.

10. Harlow S., Hill K. Assessing Library Online Patrons Use of Resources to Improve Outreach and Marketing // The Serials Librarian. 2020. Vol. 78. 04 Mar 2020. DOI: 10.1080/0361526X.2019.1703873.
11. Ларина А.В., Матвеева М.С. Значение культурных кодов и стереотипов в контексте семиотики медийной туристской рекламы // Мир науки, культуры, образования. 2019. № 4 (77). C. $445-447$.

12. Hamlett A., Georgas H. In the Wake of Discovery: Student Perceptions, Integration, and Instructional Design // Journal of Web Librarianship. 2019. Vol. 46, № 1. P. 230-245. DOI: 10.1080/19322909.2019.1598919.

13. Vakkari P., Mikkonen A. The Role of Readers' Literary Preferences in Predicting Success in Fiction Search // Journal of Documentation. 2019. Vol. 76, № 1. P. 317-332. DOI: 10.1108/JD-01-2019-0005.

14. Khan A., Masrek M., Mahmood K. The Relationship of Personal Innovativeness, Quality of Digital Resources and Generic Usability with Users' Satisfaction: A Pakistani Perspective // Digital Library Perspectives. 2019. Vol. 35, № 1. P. 15-30. DOI: 10.1108/DLP-12-2017-0046.

15. Борисова О.О., Степина Н.А. Независимая оценка качества предоставления услуг : (из опыта работы централизованной библиотечной системы г. Орла) // Культура: теория и практика. 2020. № 1 (34). C. $75-84$.

16. Lo P., He M., Liu Y. Social Inclusion and Social Capital of the Shanghai Library as a Community Place for SelfImprovement // Library Hi Tech. 2019. Vol. 37, № 2. P. 197-218. DOI: 10.1108/LHT-04-2018-0056.

17. Sundareswaran N. User Perception of Library Services in Public Libraries in Western Tamilnadu with Special Reference to Salem District: a Case Study // Library Philosophy and Practice (e-journal). 2019 [Электронный ресурс]. URL: https://digitalcommons. unl.edu/libphilprac/2951/ (дата обращения: 18.05.2020).

18. Веселкова Н.В. Методические принципы полуформализованного интервью // Социология: методология, методы, математическое моделирование. 1995 . № 5-6. С. 28-47.

19. Чеховский И.В. Интервью как способ получения информации в качественной стратегии исследовательского поиска // Вестник Российского университета дружбы народов. Серия: Социология. 2009. № 4. C. 20-25.

20. Рыхторова А.Е. Сегментирование пользователей для развития библиотечных сайтов // Информационные ресурсы России. 2019. № 2 (168). C. $20-24$.

21. Pyati A.K. Public Libraries as Contemplative Spaces: A Framework for Action and Research // Journal of the Australian Library and Information Association. 2019. Vol. 68, № 4. P. 356-370. DOI: 10.1080/24750158.2019.1670773. 


\title{
Analyzing and Building an Advertising Image of the Library through User Interviews
}

\author{
Anna E. Rykhtorova, \\ State Public Scientific Technological Library of the Siberian Branch of the Russian Academy of Sciences, \\ 15 Voskhod Str., Novosibirsk, 630102, Russia \\ ORCID 0000-0001-7790-8226; SPIN 7923-2290 \\ E-mail: rykhtorova@gpntbsib.ru
}

\begin{abstract}
Over the past decades, advertising for the library has become a mandatory part of the activity, but the approach to its creation is largely based on accepted stereotypes that express the most common ideas about the properties of such a complex phenomenon as the target audience of the library. Advertising can be expressed through an advertising image that contains not only objective but also subjective information; it uses associations, metaphors, emotions, visualization of something that has a generalizing character, i. e. a layer of implicit information is added to the exact data and read automatically. One of the problems of creating an advertising image may be that there are contradictions between the perception of the person who creates an advertising based on a stereotype and its recipient. The article reflects the experience of the State Public Scientific Technological Library of the Siberian Branch of the Russian Academy of Sciences (SPSTL SB RAS) in the study of two groups - "Event visitors" and "Readers". The study involved 326 people (254 visitors to mass events and 72 readers of the SPSTL SB RAS). The author tested the method of semiformalized interview to get relevant information for better understanding the audience's motivation and desires. It is assumed to use pre-made plan with a list of mandatory questions, while using general wording and their variations, "close to the text", and observing the general logic in their sequence.

The author analyses the data on distribution of users in both groups ("Event visitors" and "Readers") by the age categories and employment areas; frequency of library visits; frequency of references to forms of work that are called in demand and found interesting in both groups; frequency of references to preferred information channels. The article presents the main positions for creating an advertising image of the library. The author shows the expediency of using the semi-formalized interview method to adjust the advertising image of the library and the campaign to promote events, resources and services based on it, both for individual groups and for several segments in parallel, if the library's event or service does not have a specific addressee. The article reveals the method of work that can be applied in the analysis of the advertising image for other libraries.
\end{abstract}

Key words: organization of librarianship, advertising activities of library, advertising image of library, library marketing, interview, target audience of library, reader, user study, reader study.

Citation: Rykhtorova A.E. Analyzing and Building an Advertising Image of the Library through User Interviews, Bibliotekovedenie [Russian Journal of Library Science], 2020, vol. 69, no. 6, pp. 655-667. DOI: 10.25281/0869-608X-2020-69-6-655-667.

\section{References}

1. Adamyants T.Z. Mass Media Audience as a Subject and an Object of the Communicational Interaction, Chelovek [The Human Being], 2018, no. 3, pp. 96-107 (in Russ.).

2. Solovyov A.V. Mediacity and the Human: Distant Involvement, Chelovek [The Human Being], 2017, no. 5, pp. 100-107 (in Russ.).
3. Redkina N.S. Global Trends of Libraries Development: Optimism vs Pessimism (Foreign Literature Review). Part 1, Bibliosfera [Bibliosphere], 2019, no. 1, pp. 49-58. DOI: 10.20913/1815-3186-2019-1-49-58 (in Russ.).

4. Petersen J.H., Kooistra R.B. Rethinking Libraries in the Book Business, Public Library Quar- 
terly, 2019, vol. 13, no. 1, pp. 64-88. DOI: 10.1080/01616846.2019.1604040.

5. Shohama S., Klain-Gabbayb L. The Academic Library: Structure, Space, Physical and Virtual Use, The Journal of Academic Librarianship, 2019, vol. 45, no. 5. DOI: 10.1016/j.acalib.2019.102053.

6. Grishanin N.V., Tulubyev V.B., Lysanova D.V., Lyubetskaya A.G. The Perception of Libraries by Young Audience: The Approaches to the Formation of Publicity Capital, Kommunikologiya [Communicology], 2019, vol. 7, no. 2, pp. 51-65. DOI: $10.21453 / 2311-$ 3065-2019-7-2-51-65 (in Russ.).

7. Fernández-Ardèvol M., Ferran-Ferrer N., NietoArroyo J., Fenoll C. The Public Library as Seen by the Non-Users, Profesional de la información, 2018, vol. 27, no. 3, pp. 659-670. DOI: 10.3145/epi.2018. may.19.

8. Leshukov A.G., Chebotarev A.M. Design of Communication Products: Current Trends in the Cultural Space of the City, Vestnik kul'tury i iskusstv [Culture and Arts Herald], 2018, no. 4 (56), pp. 97-103 (in Russ.).

9. Savchenko D.G. About the Concept of Advertising Image, Vestnik Moskovskogo gosudarstvennogo lingvisticheskogo universiteta. Gumanitarnye nauki [Vestnik of Moscow State Linguistic University. Humanities], 2018, no. 18 (816), pp. 308-319 (in Russ.).

10. Harlow S., Hill K. Assessing Library Online Patrons Use of Resources to Improve Outreach and Marketing, The Serials Librarian, 2020, vol. 78. Published online: 04 Mar 2020. DOI: 10.1080/0361526X.2019.1703873.

11. Larina A.V., Matveeva M.S. The Importance of Cultural Codes and Stereotypes in the Context of Semiotics of Media Tourist Advertisement, Mir nauki, kul'tury, obrazovaniya [The World of Science, Culture and Education], 2019, no. 4 (77), pp. 445-447 (in Russ.).

12. Hamlett A., Georgas H. In the Wake of Discovery: Student Perceptions, Integration, and Instructional Design, Journal of Web Librarianship, 2019, vol. 46, no. 1, pp. 230-245. DOI: 10.1080/19322909.2019.1598919.

13. Vakkari P., Mikkonen A. The Role of Readers' Literary Preferences in Predicting Success in Fiction
Search, Journal of Documentation, 2019, vol. 76, no. 1, pp. 317-332. DOI: 10.1108/JD-01-2019-0005.

14. Khan A., Masrek M., Mahmood K. The Relationship of Personal Innovativeness, Quality of Digital Resources and Generic Usability with Users' Satisfaction: A Pakistani Perspective, Digital Library Perspectives, 2019, vol. 35, no. 1, pp. 15-30. DOI: 10.1108/DLP-12-2017-0046.

15. Borisova O.O., Stepina N.A. Independent Assessment of the Quality of Service Delivery (From the Experience of the Centralized Library System in Orel), Kul'tura: teoriya i praktika [Culture: Theory and Practice], 2020, no. 1 (34), p. 75-84 (in Russ.).

16. Lo P., He M., Liu Y. Social Inclusion and Social Capital of the Shanghai Library as a Community Place for Self-Improvement, Library Hi Tech, 2019, vol. 37, no. 2, pp. 197-218. DOI: 10.1108/LHT-042018-0056.

17. Sundareswaran N. User Perception of Library Services in Public Libraries in Western Tamilnadu with Special Reference to Salem District: a Case Study, Library Philosophy and Practice (e-journal), 2019. Available at: https://digitalcommons.unl.edu/ libphilprac/2951/ (accessed 18.05.2020).

18. Veselkova N.V. Methodological Principles of a SemiFormalized Interview, Sotsiologiya: metodologiya, metody, matematicheskoe modelirovanie [Sociology: Methodology, Methods and Mathematical Modeling], 1995, no. 5-6, pp. 28-47 (in Russ.).

19. Chekhovsky I.V. Interview as a Tool to Obtain Information in Qualitative Research Strategy, Vestnik Rossiiskogo universiteta druzhby narodov. Seriya: Sotsiologiya [RUDN Journal of Sociology], 2009, no. 4, pp. 20-25 (in Russ.).

20. Rykhtorova A.E. User Segmentation for the Development of Library Websites, Informatsionnye resursy Rossii [Information Resources of Russia], 2019, no. 2 (168), pp. 20-24 (in Russ.).

21. Pyati A.K. Public Libraries as Contemplative Spaces: A Framework for Action and Research, Journal of the Australian Library and Information Association, 2019, vol. 68, no. 4, pp. 356-370. DOI: 10.1080/24750158.2019.1670773. 